\title{
Oxidant and antioxidant status of human breast milk during lactation period
}

\author{
Sevda Yuksel • Ayse Arzu Yigit • Miyase Cinar • \\ Nurgul Atmaca • Yuksel Onaran
}

Received: 3 October 2014 / Revised: 16 December 2014 / Accepted: 16 December 2014 /

Published online: 3 March 2015

(C) INRA and Springer-Verlag France 2015

\begin{abstract}
Due to the oxidative stress conditions at birth, newborn needs some immunological and antioxidative protection after birth. The present study was conducted to point out the oxidant and antioxidant activity of human breast milk throughout the lactation. For this purpose, the levels of malondialdehyde, nitric oxide, lactoferrin, superoxide dismutase, and catalase was determined in colostrum, transition milk, and mature milk. Milk samples were collected from 20 volunteer mothers at $24-48 \mathrm{~h}$ of delivery and 7 and 14 days after delivery. The skimmed milk was used for determination of the levels of malondialdehyde, nitric oxide, and lactoferrin and the activities of the catalase and superoxide dismutase enzymes. As the lactation period proceeded, the malondialdehyde level increased and the levels of nitric oxide and lactoferrin as well as the activities of catalase and superoxide dismutase decreased. Colostrum has a high antioxidant capacity, and these antioxidants decrease during the lactation period owing to the changing need of the growing infant. The results of this study revealed the importance of breastfeeding immediately after the birth to take the advantage of colostrum.
\end{abstract}

\section{S. Yuksel}

Department of Child Development, School of Health, Turgut Ozal University, 06374 Ankara, Turkey

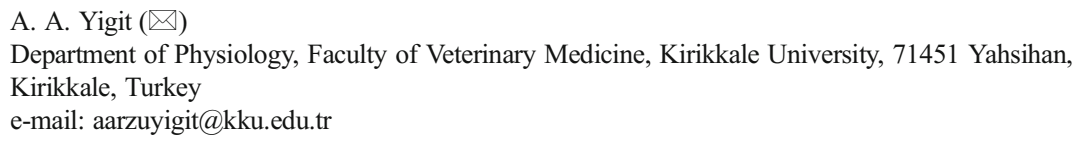

M. Cinar

Department of Biochemistry, Faculty of Veterinary Medicine, Kirikkale University, 71451 Yahsihan, Kirikkale, Turkey

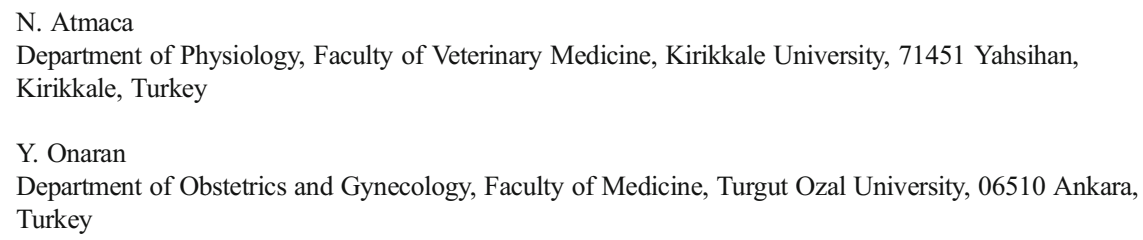


Keywords Antioxidant $\cdot$ Colostrum $\cdot$ Malondialdehyde $\cdot$ Mature milk $\cdot$ Transition milk

\section{Introduction}

Human milk contains hormones, growth factors, and immunological factors such as cytokines; it also has antioxidant properties. It not only provides passive protection but also can directly modulate the immunological development of infants. These features of human milk protect the infant from infections (Garofalo 2010).

Free radicals or, more generally, reactive oxygen species (ROS) and reactive nitrogen species (RNS) are products of cellular metabolism. They have both deleterious and beneficial effects in living organisms (Valko et al. 2006). The harmful effects of free radicals cause many disease in newborns, such as necrotizing enterocolitis, bronchopulmonary dysplasia, kidney failure, retinopathy of prematurity, and intraventricular hemorrhage (Schaller 2005). In response, mammalian cells have developed antioxidant defense mechanisms that prevent ROS- and RNS-induced damage. If the balance between free radicals and antioxidants deteriorates, pathological processes develop (Agarwal et al. 2008).

Delivery is an important stress for the fetus. Lipid peroxidation and antioxidant status change during delivery, and these changes affect the fetus (Buonocore and Perrone 2006). Malondialdehyde (MDA) is a final lipid peroxidation product and it is the most widely used indicator of the degree of the oxidation process in body fluids (Schauer et al. 1991). Oxidant activity of breast milk also reflects the oxidant status of blood (Bouwstra et al. 2008).

Studies show that breast milk can suppress the effects of oxidative stress and oxidative DNA damage in newborns more than formula milk can (Shoji et al. 2004). Antioxidant enzymes such as superoxide dismutase (SOD) and catalase (CAT), which prevent the formation of radicals or hydrogen peroxide and other peroxides, as well as glutathione peroxidase (GPX), which catalyzes the reduction of different peroxides, have been demonstrated in milk. In addition, human milk contains non-enzymatic antioxidants such as lactoferrin (LF), vitamin C, and vitamin E (Lindmark-Mansson and Akesson 2000). LF is a metal- and anion-binding protein. It shows bactericidal and antiviral effects competing with microorganisms requiring iron for growth (Goldman et al. 1994). High antioxidant activity of breast milk protects breast-fed infants from peroxidation caused by free radicals (Ellis et al. 1990).

Total antioxidant capacity (Matos et al. 2009; Zarban et al. 2009), Mn-superoxide dismutase (MnSOD) activity, and CuZn superoxide dismutase (CuZnSOD) activity (Kasapovic et al. 2005) have previously been determined in colostrum, transitional milk, and mature human milk. In addition, some antioxidant micronutrients have been shown in colostrum (Ahmed et al. 2004) and milk from the first 4 months of breastfeeding (Matos et al. 2009). Despite the well-known role of the antibodies in colostrum that provide the passive immunity, information about the breast milk antioxidant activity is still insufficient. Also, the determination of antioxidant activity of breast milk may be helpful for understanding its natural defense system.

Therefore, the aim of this study was to determine the levels of malondialdehyde (MDA), nitric oxide (NO), and lactoferrin (LF) and the activities of SOD and CAT in milk from different periods of lactation. 


\section{Methods}

This study was conducted in the Department of Obstetrics and Gynecology at Turgut Ozal University Hospital. Twenty participants were recruited randomly from those admitted to the hospital. Written consent was obtained from all women, and the study was approved by the local ethics committee (2009/17) in accordance with the Helsinki Declaration of 1975, as revised in 1983.

All mothers were in the age range of 20-30 years and had completed 38-40 weeks of pregnancy. They were of similar weight, nulliparous, healthy, and non-smoking. All women had uncomplicated singleton pregnancies. None of them had any abnormalities during delivery, and all delivered vaginally at term without anesthesia.

Five milliliters of colostrum, transitional milk, and mature milk were collected from each breast by manual expression within $24-48 \mathrm{~h}$ of delivery and at 7 and 14 days after delivery. Whole milk samples were first centrifuged at $500 \times g$ for $25 \mathrm{~min}$ at $4{ }^{\circ} \mathrm{C}$ to remove any cellular components. Then, they were centrifuged at $13,700 \times g$ for $10 \mathrm{~min}$ at $4{ }^{\circ} \mathrm{C}$ to remove its lipid layer. All samples were divided into five aliquots for each analysis and stored at $-80{ }^{\circ} \mathrm{C}$. The skimmed milk was used for determining the levels of MDA, NO, and LF as well as the activities of the SOD and CAT enzymes. Samples for NO and SOD were deproteinized with $10 \% \mathrm{ZnSO}_{4}$ and filtered using a syringe filter (pore size $0.45 \mu \mathrm{m}$ ) to obtain transparent milk samples before analysis. The concentration of MDA was determined as thiobarbituric acid-reactive substances using the spectrophotometric method of Buege and Aust (1978). The activities of CAT and SOD and the levels of NO were evaluated by double reading using colorimetric assay kits (catalog nos. 707002, 706002, and 78000,1 respectively, Cayman Chemical Company, Ann Arbor, MI, USA). The LF levels were measured with an ELISA kit (catalog no. EL2011-1, Assaypro, USA).

Data were expressed mean \pm standard error of the mean (SEM). Statistical analysis was performed using SAS (version 8.02, SAS Institute, USA). Data from the three periods of lactation were analyzed using the general linear model procedure. The Tukey test was used to identify the differences among the groups. Differences were considered as significant when the $P$ value was less than 0.05. Figures were drawn with Origin 6.0.

\section{Results}

As shown in Fig. 1, the MDA levels were $1.49 \pm 0.08,1.78 \pm 0.11$, and $2.14 \pm$ $0.11 \mu \mathrm{M} . \mathrm{L}^{-1}$ in colostrum, transition milk, and mature milk, respectively. Although statistical difference was only observed in mature milk $(P<0.05)$, the MDA level increased as the lactation period progressed. The NO level was higher $(119.23 \pm$ $6.11 \mu \mathrm{M})$ in colostrum $(P<0.05)$ than in transition milk and mature milk $(102.16 \pm$ 3.29 and $93.54 \pm 3.40 \mu \mathrm{M}$, respectively; Fig. 2). Similarly, in the colostral phase, the level of LF was significantly $(P<0.05)$ higher $\left(16.29 \pm 0.69\right.$ g. $\left.\mathrm{L}^{-1}\right)$ than in the 7 th and 14th days (12.49 \pm 0.12 and $13.7 \pm 0.57$ g. $\mathrm{L}^{-1}$, respectively; Fig. 3$)$. As shown in Fig. 4, CAT activity was the highest $\left(26.21 \pm 2.78 \mathrm{nmol} \cdot \mathrm{min}^{-1} \cdot \mathrm{mL}^{-1}\right)$ in the colostrum $(P<0.05)$, and it decreased markedly in transition milk and mature milk $(9.39 \pm 0.53$ and $1.84 \pm 0.39 \mathrm{nmol} \cdot \mathrm{min}^{-1} \cdot \mathrm{mL}^{-1}$, respectively). Finally, SOD activity in the colostrum 


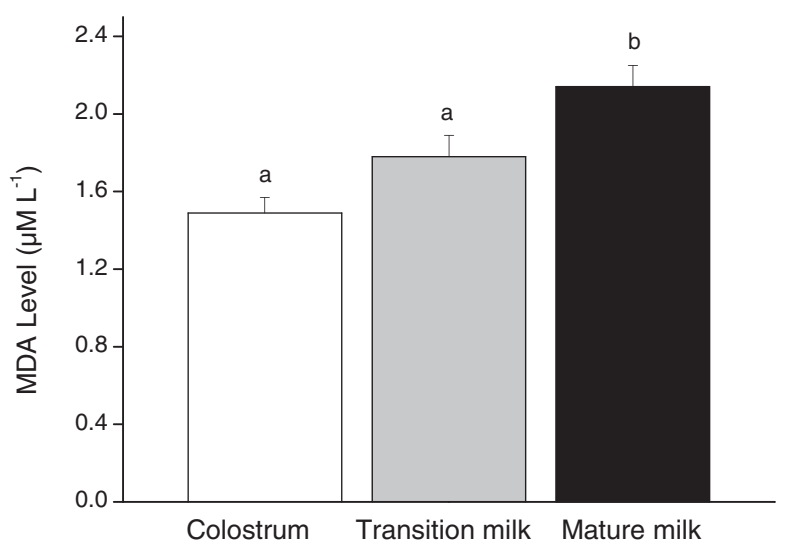

Fig. 1 Malondialdehyde $(M D A)$ levels in colostrum, transition milk, and mature milk $(n=20)$. $a, b P<0.05$

$\left(6.26 \pm 0.7\right.$ nmol.min $\left.{ }^{-1} \cdot \mathrm{mL}^{-1}\right)$ was higher than that in transition milk and mature milk $\left(2.93 \pm 0.25\right.$ and $2.01 \pm 0.27$ nmol.min $\left.{ }^{-1} \cdot \mathrm{mL}^{-1}\right)$, as shown in Fig. $5(P<0.05)$.

\section{Discussion}

The process of childbirth is an important stress for the fetus, which passes from an intrauterine, hypoxic environment into an extrauterine, normoxic environment (Buege and Aust 1978). Consequently, the newborn is exposed to environmental stress at birth. For this reason, the antioxidant defense against ROS-induced lipid peroxidation (LPO) after birth should be very strong. The total antioxidant capacity (TAC) of the colostrum was significantly higher than that of umbilical blood (Zhao et al. 2004). Human milk contains a number of enzymes that are either transported by blood to the mammary gland or synthesized by the mammary gland itself. Although the complete list of active antioxidant factors in breast milk is not known, CAT, SOD, GPX, and LF are wellknown milk antioxidants. They show an antioxidative effect either by connecting to

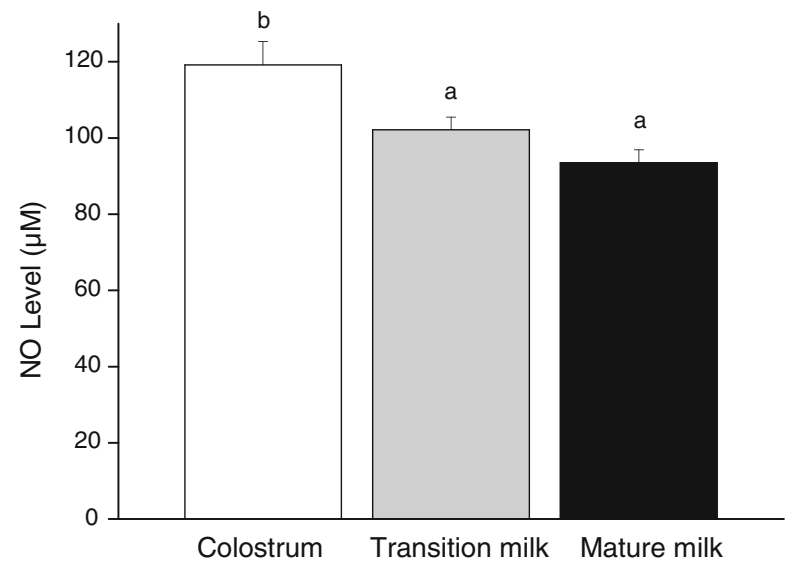

Fig. 2 Nitric oxide $(N O)$ levels in colostrum, transition milk, and mature milk $(n=20)$. $a, b P<0.05$ 


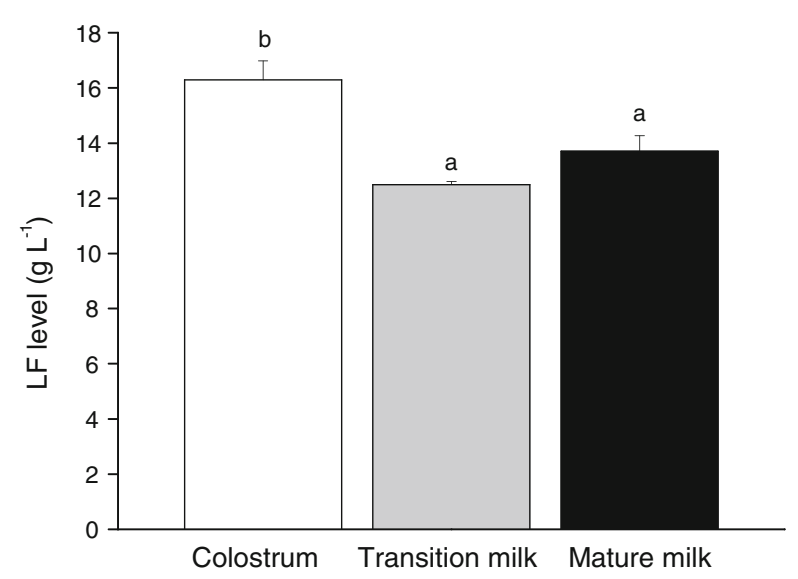

Fig. 3 Lactoferrin $(L F)$ levels in colostrum, transition milk, and mature milk $(n=20)$. a, b $P<0.05$

transition metal ions or by removing free radicals via enzymatic and non-enzymatic reactions (Kasapovic et al. 2005).

MDA, a metabolite of lipid peroxides, is detectable in milk and is used as an indicator of LPO. Studies have shown that breast milk possesses essential defense mechanisms, which are not available in infant formulas (Friel et al. 2002; Aycicek et al. 2006) or bovine milk (Hamosh 2001). In contrary to Szlagatys-Sidorkiewicz et al. (2012) who showed that total antioxidant status (TAS) of colostrum was lower than the TAS of mature milk, previous studies (Matos et al. 2009; Zarban et al. 2009) showed that TAC and radical scavenging activity decreased in transition milk and mature milk when it was compared with the colostrum. In the present study, the reason for the decreased MDA concentration observed in the colostrum as compared to transition milk and mature milk might be due to the increased levels of CAT, SOD, NO, and LF present in it. The increase in oxidative stress at birth might require and thus explain the high antioxidant levels observed on the 1st day of lactation.

Nitric oxide is synthesized in the breast and it may trigger lactation in humans (Iizuka et al. 1997). NO stimulates and inhibits LPO, depending on its production

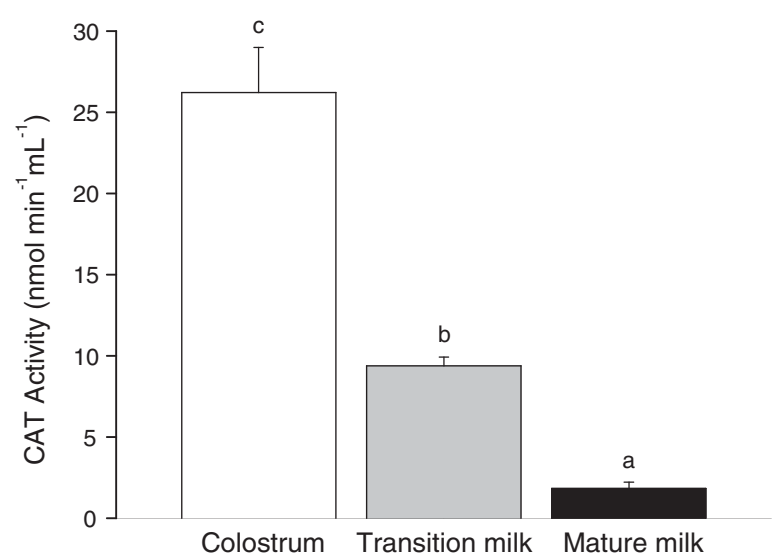

Fig. 4 Catalase (CAT) activity in colostrum, transition milk, and mature milk $(n=20) a, b, c P<0.05$ 


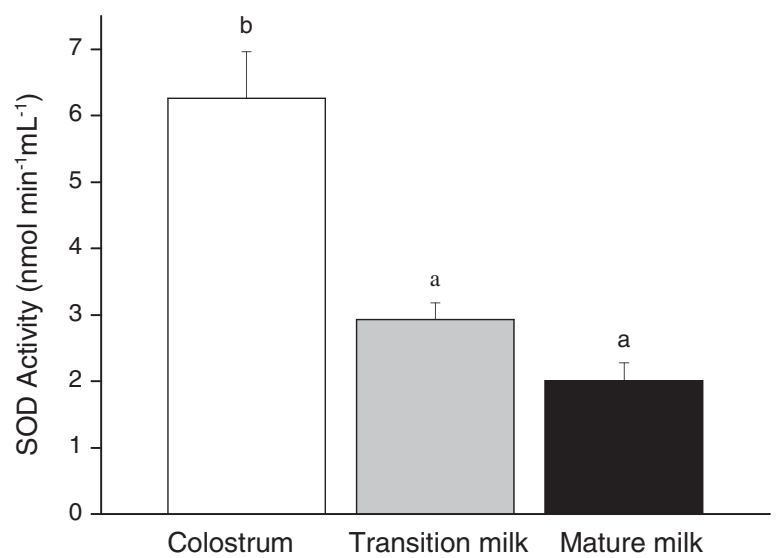

Fig. 5 Superoxide dismutase (SOD) activity in colostrum, transition milk, and mature milk ( $n=20)$. $a, b$ $P<0.05$

quantity. Peroxynitrite-dependent LPO, which usually occurs by metal-independent mechanisms, is also inhibited by NO (Rubbo et al. 1994). The fact that the highest level of NO was found in colostrum might reflect the high antioxidant feature of colostrum. In addition, high levels of NO found in colostrum could be because it acts as a trigger for lactation.

Free iron initiates and catalyzes free radical processes in biomembrane LPO. LF protects biomembranes from iron-induced LPO by binding free iron (Zimecki et al. 1995). Casein and whey proteins such as lactalbumin, lactoglobulin, lactoferrin, serum albumin, and immunoglobulins are milk proteins that exhibit antioxidant activity by ferrous-ion-chelating abilities as well as by inhibitory effects on LPO (Chiang and Chang 2005). Since the casein content of human milk is low, LF is one of the major whey proteins in human milk (Lonnerdal and Atkinson 1995), which explains the increased level of LF in the colostrum observed in this study. According to the authors, during lactation, LF concentration is higher during the first few days postpartum than after 1 week (Lewis-Jones et al. 1985). Similarly, Ella et al. (2009) determined that the LF level in the colostrum is higher than that in mature milk.

Milk CAT is a heme protein with a high molecular weight. It catalyzes the decomposition of hydrogen peroxide (Gutteridge and Halliwell 1994). In the present study, CAT activity decreased markedly as the lactation period proceeded. SOD is an essential antioxidant enzyme having an antitoxic effect against superoxide anion and catalyzes the reaction in which superoxide radicals are converted to $\mathrm{H}_{2} \mathrm{O}$ and $\mathrm{O}_{2}$. It is only found in skimmed milk (Asada 1976). Korycka-Dahl and Richardson (1979) described the production of superoxide anions in milk and the destruction of these anions by SOD. L'Abbe and Friel (2000) found that there was no difference in the SOD activity of milk from mothers of full-term infants from the 1 st to the 12th week. According to the authors, although SOD activity increased in milk from the 3 rd week of lactation as compared to colostrum, it markedly decreased in the 4th month of lactation (Kasapovic et al. 2005). In this study, the SOD activity in the colostrum was higher than that in transition milk and mature milk. The decrease in the activity of both CAT and SOD might be explained by a physiological trend in infants: while breast milk meets the needs of 
newborns in all aspects, as an infant grows up, the antioxidant effect of milk can lessen.

\section{Conclusion}

The present study shows that the MDA level in the colostrum increased. The CAT, SOD, LF, and NO concentrations showed a significant decrease as lactation proceeded. This phenomenon is thought to be the result of a decrease in the antioxidant storage of the mothers. Therefore, these findings suggest that colostrum with high antioxidant capacity is vital on the 1st day of life, and the reduction of these antioxidants during the lactation period seems to match the changing need of the growing infant. The study also revealed that the high antioxidant activity of colostrum shortly after the birth would be the most important factor for protecting newborn in his/her extra-uterine life.

Acknowledgments This research was supported by the Scientific Research Fund in the University of Kirikkale project no. 2009/04.

Conflict of interest Sevda Yksel, Ayse Arzu Yigit, Miyase Cinar, Nurgul Atmaca, and Yuksel Onaran declare that they have no conflict of interest.

\section{References}

Agarwal A, Gupta S, Sekhon L, Shah R (2008) Redox considerations in female reproductive function and assisted reproduction, from molecular mechanisms to health implications. Antioxid Redox Signal 10: 1375-1403

Ahmed L, Nazrul Islam SK, Khan MNI, Huque S, Ahsan M (2004) Antioxidant micronutrient profile (vitamin E, C, A, copper, zinc, iron) of colostrum, association with maternal characteristics. J Trop Pediatr 50:357358

Asada K (1976) Occurrence of superoxide dismutase in bovine milk. Agr Biol Chem Tokyo 40:1659-1660

Aycicek A, Erel Ö, Kocyigit A, Selek S, Demirkol MR (2006) Breast milk provides better antioxidant power than does formula. Nutrition 22:616-619

Bouwstra RJ, Goselink RMA, Dobbelaar P, Nielen M, Newbold JR, van Werven T (2008) The relationship between oxidative damage and vitamin e concentration in blood, milk, and liver tissue from vitamin $\mathrm{e}$ supplemented and nonsupplemented periparturient heifers. J Dairy Sci 91:977-987

Buege JA, Aust SD (1978) Microsomal lipid peroxidation. Methods Enzymol 52:302-310

Buonocore G, Perrone S (2006) Biomarkers of oxidative stress in the fetus and newborn. Hematology 2:103107

Chiang SH, Chang CY (2005) Antioxidant properties of caseins and whey proteins from colostrums. J Food Drug Anal 13:57-63

Ella EE, Ahmad AA, Umoh VJ, Ogala WN, Balogun TB (2009) Lactoferrin levels in human breast milk among lactating mothers with sick and healthy babies in Kaduna State, Nigeria. J Matern-Fetal Neo Med 1:495-500

Ellis L, Picciano MF, Smith AM, Hamosh M, Mehta NR (1990) The impact of gestational length on human milk selenium concentration and glutathione peroxidase activity. Pediatr Res 27:32-35

Friel JK, Martin SM, Langdon M, Herzberg GR, Buettner GR (2002) Milk from mothers of both premature and full-term infants provides better antioxidant protection than does infant formula. Pediatr Res 51:612-618

Garofalo R (2010) Cytokines in human milk. J Pediatr 156:36-40

Goldman SA, Cheda S, Keeney SE, Schmalstieg FC, Schanler RJ (1994) Immunologic protection of the premature newborn by human milk. Semin Perinatol 18:495-501

Gutteridge JMC, Halliwell B (1994) Antioxidants in nutrition, health and disease. Oxford University Press, Oxford 
Hamosh M (2001) Bioactive factors in human milk. Pediatr Clin North Am 48:69-86

Iızuka T, Sasaki M, Oishi K, Uemura S, Koike M, Shinozaki M, Minatogawa Y (1997) Nitric oxide may trigger lactation in humans. J Paediatr 131:839-843

Kasapovic J, Pejic S, Mladenovic M, Radlović N, Pajović SB (2005) Superoxide dismutase activity in colostrum, transitional and mature human milk. Turkish J Pediatr 47:343-347

Korycka-Dahl M, Richardson T (1979) Photogeneration of superoxide anion upon illumination of bovine milk serum proteins with fluorescent light in the presence of riboflavin. J Dairy Sci 62:183

L'Abbe MR, Friel JK (2000) Superoxide dismutase and glutathione peroxidase content of human milk from mothers of premature and full-term infants during the first 3 months of lactation. J Pediatr Gastroenterol Nutr 31:270-274

Lewis-Jones DI, Lewis-Jones MS, Connollly RC, Lloyd DC, West CR (1985) Sequential changes in the antimicrobial protein concentrations in human milk during lactation and its relevance to banked human milk. Pediatr Res 19:561-565

Lindmark-Mansson H, Akesson B (2000) Antioxidative factors in milk. Br J Nutr 84:103-110

Lonnerdal B, Atkinson S (1995) Nitrogenous components of milk. A. Human milk proteins. In: Jensen RG (ed) Handbook of milk composition. Academic, San Diego, pp 352-368

Matos C, Moutinho C, Balcao V, Almeida C, Ribeiro M, Margues AF, Guerra A (2009) Total antioxidant activity and trace elements in human milk, the first 4 months of breast-feeding. Eur Food Res Technol 230:201-208

Rubbo H, Radi R, Trujillo M, Telleri R, Kalyanaram B, Barnes S, Kirk M, Freeman BA (1994) Nitric oxide regulation of superoxide and peroxynitrite-dependent lipid peroxidation. Formation of novel nitrogencontaining oxidized lipid derivates. J Biol Chem 269:26066-26075

Schaller B (2005) Prospects for the future, the role of free radicals in the treatment of stroke. Free Radical Biol Med 38:411-425

Schauer RJ, Zollner H, Esterbauer H (1991) Biological effects of aldehydes with particular attention to 4hydroxynonenal and malondialdehyde. In: Vigo-Pelfrey C (ed) Membrane lipid oxidation. CRC Press, Boca Raton, FL, pp 141-163

Shoji H, Shinohara K, Oguchi S, Shiga S, Yamashiro Y (2004) Suppressive effects of breast milk on oxidative DNA damage in very low birth-weight infants. Arch Dis Child Fetal Neonatal Ed 89:F136-F138

Szlagatys-Sidorkiewicz A, Zagierski M, Jankowska A, Łuczak G, Macur K, Bączek T, Korzon M, Krzykowski G, Martysiak-Żurowska D, Kamińska B (2012) Longitudinal study of vitamins A, E and lipid oxidative damage in human milk throughout lactation. Early Hum Dev (Ireland) 88(6):421-424

Valko M, Rhodes CJ, Moncol J, Izakovic M, Mazur M (2006) Free radicals, metals and antioxidants in oxidative stress-induced cancer. Chem Biol Interact 160:1-40

Zarban A, Taheri F, Chahkandi T, Sharifzadeh G, Khorashadizadeh M (2009) Antioxidant and radical scavenging activity of human colostrum, transitional and mature milk. J Clin Biochem Nutr 45:150-154

Zhao J, Liu XJ, Ma JW, Zheng RL (2004) DNA damage in healthy term neonate. Early Hum Dev 77:89-98

Zimecki M, Mazurier J, Spik G, Kapp JA (1995) Human lactoferrin induces phenotypic and functional changes in murine splenic B cells. Immunology 86:122-127 